\title{
A New Iron Loss Model for Brushless Doubly- Fed Machines with Hysteresis and Field Rotational Losses
}

\author{
Salman Abdi, Ehsan Abdi, Senior Member, IEEE and Richard McMahon
}

\begin{abstract}
The brushless doubly-fed machine (BDFM) has two stator windings with different pole numbers, supplied with different frequencies. Therefore, the distribution of magnetic fields in stator and rotor iron is complex. In addition, the stator flux density distribution is non-sinusoidal and has a DC offset at the natural speed. This makes the use of conventional hysteresis models utilised for sinusoidal fields impractical for the BDFM. In this paper a new hysteresis model is proposed for the BDFM stator iron based on the scalar Preisach model. The rotational characteristics of the magnetic fields in the BDFM are also considered and their effects in generating iron losses are assessed. 2-D time-stepping finite element (FE) models are developed for a prototype D160 BDFM to estimate iron losses and are validated by experiments.
\end{abstract}

Index Terms-- Brushless Doubly Fed Machine (BDFM), Epstein frame, Finite element analysis, Hysteresis models, Iron loss calculation, Rotational magnetic fields.

\section{INTRODUCTION}

$\mathrm{T}$ HE Brushless Doubly Fed Machine (BDFM), previously known as self-cascaded machine [1], is an adjustable speed $\mathrm{AC}$ electrical machine and can operate as both a generator and a motor. The machine could be conceptually considered as two induction machines of different pole numbers and hence different synchronous speeds for the same supply frequency, with their rotors connected together both physically and electrically.

The most promising applications for the BDFM are those requiring variable speed operation with limited speed range so the advantage of a partially-rated convertor can be realised. The advantages of fractional converter and adjustable power factor have already promoted the use of doubly-fed induction generator in wind power generation [2]. The BDFM maintains these advantages but also achieves brushless operation which, particularly for offshore installations, would be of considerable benefit; it reduces the failure rate of generators in wind turbines [3]. In addition, because the BDFM is a medium-speed machine, its gearbox system is simplified from three stages to two or one stage, reducing the cost and weight of drive train system and increasing the reliability.

The BDFM has two stator windings with different pole numbers, supplied with different frequencies [4]. Therefore, the distribution of magnetic fields in stator and rotor iron is complex. In addition, the motion of magnetic flux is not a simple rotation as in induction machines [5]. In an ordinary squirrel cage induction machine and under normal operating conditions, the slip is relatively low and therefore the rotor core loss could be neglected. But the rotor electrical frequency in the BDFM is relatively high and can be as high as $30 \mathrm{~Hz}$. For this reason and due to the existence of rotor field spatial harmonics and rotor current time harmonics, the iron loss in the BDFM is higher than that of conventional induction machines. Moreover, iron losses can affect flux and torque dynamic responses. Therefore, accurate modelling of iron loss for the BDFM is essential in order to optimise the design and performance of the machine.

Several works have been reported on the modelling of the BDFM virtually as the connection of two induction motors with different pole numbers with their rotors electrically and mechanically connected known as the Cascaded Doubly Fed Machine (CDFM) [6]. However, in modern BDFMs where both stator windings are wound in a single frame, more complexity arises especially when the stator hysteresis loss is to be analysed. This is because two simultaneous stator fields exist in the same air gap in the BDFM while there is only one field in each air gap of a CDFM. In addition, the nonlinearity of the machine due to the presence of hysteresis effect does not allow the principle of superposition to be generally applied. This subject was studied in [7] using the concepts of dissipation and restoring functions. It was assumed that all the elements of iron losses including eddy current and hysteresis losses of both stator and rotor can be considered separately, but the fact that the stator hysteresis loss from the two fields cannot be decoupled, was neglected.

An important contribution to investigating the iron loss in the BDFM is due to Ferreira [8]. They incorporated the iron loss model using the conventional three-component equation i.e. hysteresis, eddy current and excess losses, in finite element time-stepping analysis, and compared the calculated input power with measurements at the same operating conditions. However, applying the conventional iron loss model to the BDFM did not give accurate results mainly because the assumption of sinusoidal magnetic field distribution cannot be made for the BDFM stator iron circuit. Zhang et. al. [9] used a similar method for iron loss calculation with additional consideration for the rotational effects of the magnetic fields, however, no experimental iron loss measurement was reported.

Hashemnia et. al. [10] added parallel iron loss resistances to the BDFM's equivalent circuit with an aim to improve stead-

S. Abdi is with School of Engineering, University of East Anglia (UEA), Norwich, NR4 7TJ, UK (e-mail: s.abdi-jalebi@uea.ac.uk).

E. Abdi is with Wind Technologies Ltd, St. Johns Innovation Park, Cambridge, CB4 0WS, UK (e-mail: ehsan.abdi@windtechnologies.com).

R. McMahon is with Warwick Manufacturing Group (WMG), University of Warwick, Coventry, CV4 7AL, UK (e-mail: r.mcmahon.1@ @arwick.ac.uk). 
state performance predictions. The resistances were computed by considering the BDFM as a CDFM and taking into account the slip of the rotor with respect to the PW and CW. This, in part, improved equivalent circuit's estimation of the steadystate performance, but considerable mismatch between experimental and simulation results remained, because the effects of the BDFM's complex magnetic fields in the calculation of stator hysteresis loss were ignored.

$\mathrm{Yu}$ et. al. [11] proposed a vector hysteresis model to calculate the iron losses in the BDFM, but the effects of eddy current and excess losses were ignored and no experimental verification was presented. A number of studies have been conducted on the modelling of iron losses in Brushless Doubly Fed Reluctance Machines [12, 13]. In [12], a modified equivalent circuit was proposed which incorporates iron loss effects. A 2-D finite element method with each lamination modelled individually was used, as the prototype machine was axially laminated. It was shown that the rotor in an axially laminated machine produces higher iron losses, which will affect the efficiency and thermal stability of the machine. However, no generic iron loss model capable of predicting different iron losses at different operating conditions was provided.

This paper proposes a new iron loss model for the BDFM drawing from the conventional three-termed iron loss model for electrical machines i.e. eddy current loss, excess loss and hysteresis loss. The method utilises the magnetic field obtained for each element of the iron circuit from FE analysis to calculate the iron losses in that element. It is therefore based on the postprocessing of the FE analysis. The main contribution of this paper is the use of scalar Preisach model to estimate the hysteresis losses in the BDFM, as well as taking into account variable loss coefficients and the rotational characteristics of the magnetic field in the stator and rotor iron in generating iron losses.

\section{BRUSHLESS DOUBLY FED INDUCTION MACHINES}

The BDFM has two sets of balanced three-phase stator windings which produce two fields of different pole numbers $\left(2 P_{1}\right.$ and $\left.2 P_{2}\right)$. The pole numbers are selected in a way to avoid direct transformer coupling between the stator windings and the coupling between the windings is through the rotor. For this purpose, $P_{1}$ and $P_{2}$ must be different from each other. The rules for choosing pole numbers for the stator windings are discussed in [14].

The rotor has a short-circuited configuration and couples the fields of both stator windings by induction. The nested-loop design, which was first proposed by Broadway and Burbridge in [1], is the most widely used, although other configurations are possible [15].

Typically, there are three different operating modes for the BDFM. Induction mode is obtained by connecting one stator winding to the supply and leaving the other winding open. The characteristics of the machine in this mode are the same as those of a standard induction machine, but with poorer performance. If the non-connected stator winding is short-circuited, the behavior of the machine will be similar to an induction machine with $P_{1}+P_{2}$ pole pairs, which is called the cascade mode.

The previous two modes are both asynchronous operating modes in which the shaft speed is dependent on the loading of the machine as well as the supply frequency. However, the third and desirable mode of operation for which the design of the machine is optimised, is the synchronous mode and is used for controlled variable-speed operation [16]. In this mode, one winding, the power winding $(\mathrm{PW})$ is connected directly to the grid and the other winding, the control winding $(\mathrm{CW})$, is supplied with variable voltage at variable frequency from a converter also connected to the grid. A schematic of the BDFM and the way it is connected to the grid is shown in Fig. 1. In the synchronous mode, the speed of the rotor shaft in rpm is a function of the supplied frequencies of two stator windings $\left(f_{1}\right.$ and $f_{2}$ ) given by:

$$
n_{r}=60 \frac{f_{1}+f_{2}}{p_{1}+p_{2}}
$$

\section{The Proposed IRON Loss Modelling OF THE BDFM}

The iron losses can be conventionally separated into three categories: eddy current loss, excess loss and hysteresis loss [8].

$$
\begin{aligned}
& P_{c}=P_{e}+P_{e x}+P_{\text {hyst }}= \\
& K_{e} f^{2} B^{2}+K_{e x} f^{1.5} B^{1.5}+K_{\text {hyst }} f B^{2}
\end{aligned}
$$

These losses are functions of the magnetic flux density and frequency i.e. B and $f$, and lamination material characteristics, which are reflected in $\mathrm{K}_{\mathrm{e}}, \mathrm{K}_{\mathrm{ex}}$ and $\mathrm{K}_{\text {hyst }}$ factors. The prediction of these loss terms requires knowledge of the field distribution in the iron as a function of time. This may be computed using a finite element model or a magnetic equivalent circuit model [10]. The computation of flux density distribution in the finite element method is more precise, hence the distribution of core losses can be computed more accurately.

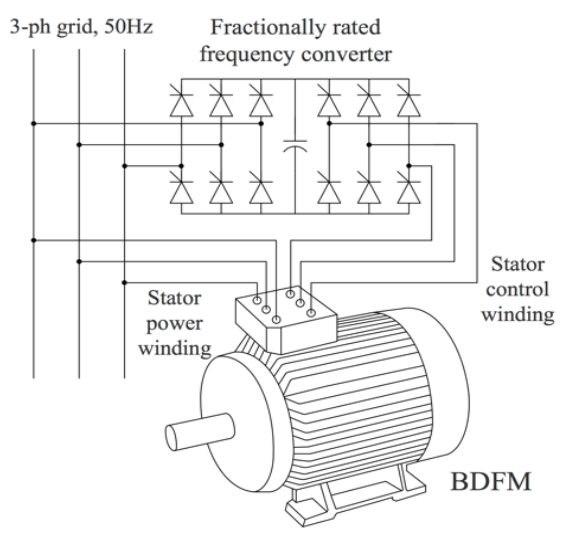

Fig. 1. Stator PW and CW grid connection.

\section{A. Rotational Magnetic Field in the BDFM}

The rotational variations of flux vectors in the core cause iron losses to increase compared with the situation in which there is only an alternating field. In the presence of rotational magnetic fields, not only there is a $180^{\circ}$ movement of the domain wall, but also a $90^{\circ}$ shift occurs [17]. A higher rotational variation of the flux vectors leads to more iron losses. The 
conventional equation for calculating the iron losses given in (2) accounts only for the losses in a lamination with a purely alternating field and do not take into account the calculation of the losses produced by rotating fields.

A simple approach to estimate the iron losses is to apply the conventional equation to the component of flux density along its major axis only. This approach entirely neglects the contribution of the minor axis component [18]. A more accurate approximation is to take into account the losses produced by the major and minor axes components of the field independently and summing them up to estimate the total rotational losses [19]. It is shown in [19] that this approach can lead to the estimation of iron losses with acceptable accuracy.

In order to investigate the rotational behaviour of the magnetic fields in a machine's iron circuit, Kochmann [20] proposed using an aspect ratio, defined as the ratio of the flux along the minor axis $\left(B_{\text {minor }}\right)$ to that along the major axis $\left(B_{\text {major }}\right)$ of the flux density locus:

$$
\lambda=\frac{\left|B_{\text {minor }}\right|}{\left|B_{\text {major }}\right|}
$$

A value of zero corresponds to a pure alternating field; and the closer the ratio is to 1 , the more the nature of flux density is rotational. The aspect ratio is used in our study to investigate the rotational behavior of the magnetic fields in the BDFM.

The FE models have been developed for a prototype BDFM with specifications shown in Table I. The radial and tangential components of flux density, i.e. $B_{r}$ and $B_{t}$ respectively, in various locations in the stator and rotor iron shown in Figs. 2 and 3 , are obtained by post-processing of FE simulation data. The values of $B_{\text {minor }}, B_{\text {major }}$, and aspect ratio $(\lambda)$ when the BDFM is operating in the synchronous mode and at rated conditions are shown in Table II. The loci of flux density for the stator and rotor tooth tip and back iron (points $\mathrm{P}_{2}$ and $\mathrm{P}_{7}$ in Figs. 2 and 3) are shown in Fig. 4.

TABLE I

SPECIFICATIONS OF THE PROTOTYPE BDFM

\begin{tabular}{lclc}
\hline Frame size & D160 & PW rated flux density & $0.28 \mathrm{~T}$ \\
Stack length & $190 \mathrm{~mm}$ & CW rated flux density & $0.34 \mathrm{~T}$ \\
Lamination & M530- & Rated speed & $700 \mathrm{rpm}$ \\
& $65 \mathrm{~A}$ & & \\
PW pole pair number & 2 & PW rated voltage & $415 \mathrm{~V}$ at \\
& $40 \mathrm{~Hz}$ & $12 \mathrm{~A}$ \\
CW pole pair number & 4 & PW rated current & $415 \mathrm{~V} \mathrm{at}$ \\
Stator number of slots & 36 & CW rated voltage & $50 \mathrm{~Hz}$ \\
Rotor number of slots & 24 & CW rated current & $5.3 \mathrm{~A}$ \\
\hline
\end{tabular}

In the stator core, the region at the bottom of stator tooth $\left(P_{6}\right.$ and $P_{7}$ ) shows the largest value of $\lambda$ with the back iron being next in importance. The flux density along the tooth depth is nearly alternating as expected. The only tangential components found in the stator tooth are in $P_{1}$ and $P_{2}$ due to the leakage flux. For the rotor core, the region close to the air gap presents the largest aspect ratio. The behaviour of the field along the rotor teeth and in rotor back iron is nearly alternating.

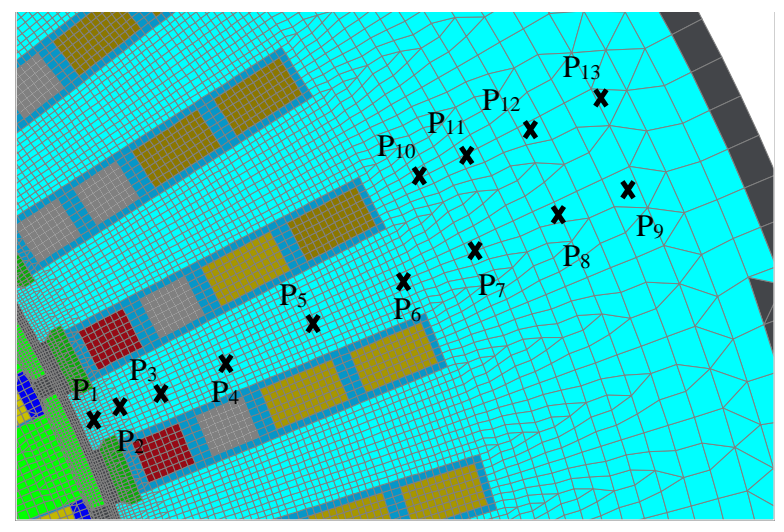

Fig. 2. Location of elements in stator iron for which flux densities are calculated.

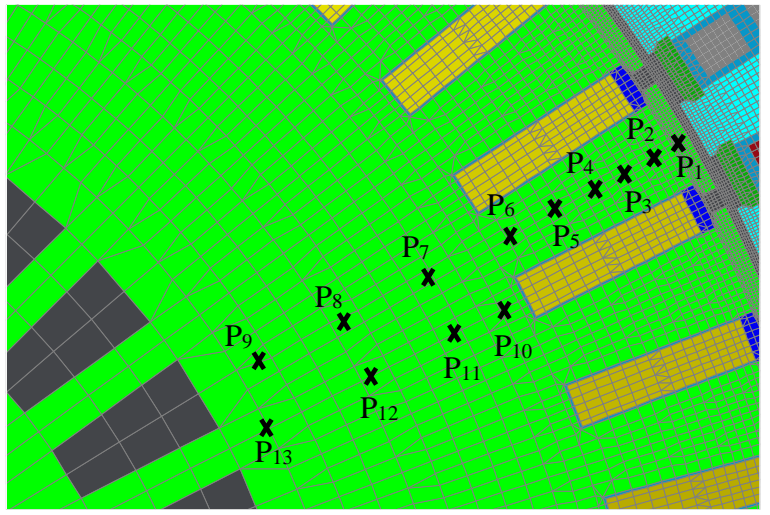

Fig. 3. Location of elements in rotor iron for which flux densities are calculated.

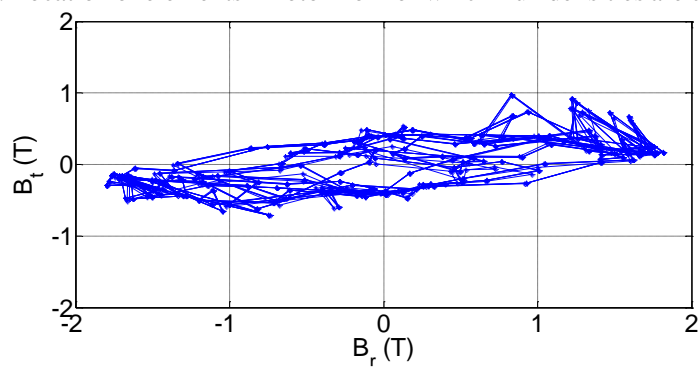

(a)

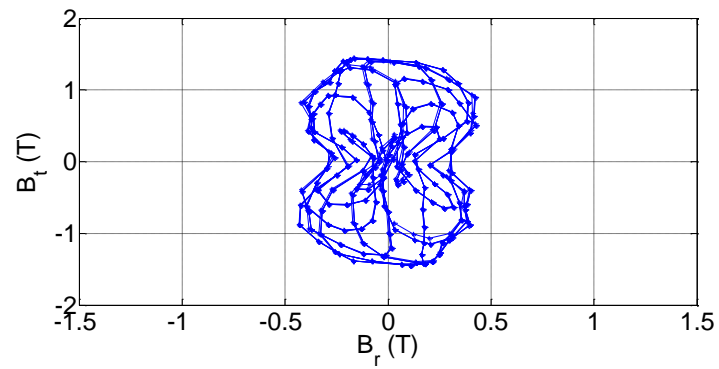

(b)

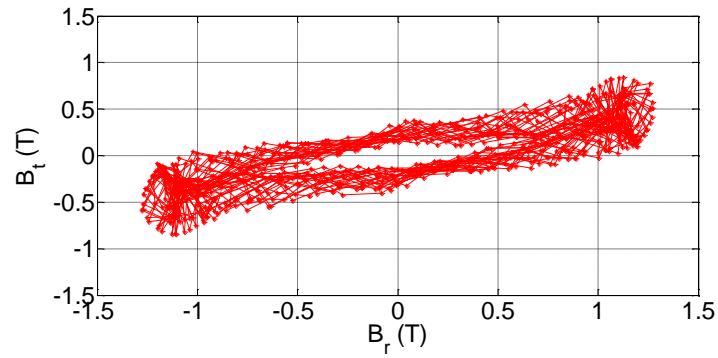

(c) 


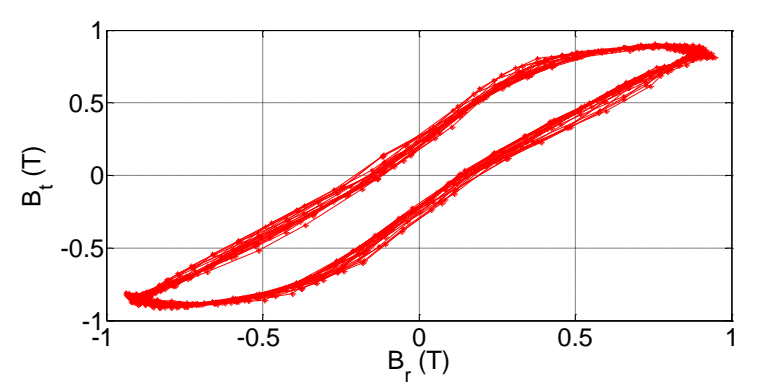

(d)

Fig. 4. Loci of $\mathrm{B}$ for: (a) stator tooth tip $\left(\mathrm{P}_{2}\right)$, (b) stator back iron $\left(\mathrm{P}_{7}\right)$, (c) rotor tooth tip $\left(\mathrm{P}_{2}\right),(\mathrm{d})$ rotor back iron $\left(\mathrm{P}_{7}\right)$.

\section{B. Eddy Current Loss}

When a conductive material is exposed to time-varying magnetic fields, loops of eddy currents are induced. Despite the fact that in electrical machines iron cores are laminated in order to reduce the flow of eddy currents, there are still losses due to the Joule's effect. The time average value of the losses is given by:

$$
P_{e}=\frac{d^{2}}{12} \frac{1}{T} \int_{T}^{(}\left(\frac{\partial B_{x}}{\partial t}\right)^{2} d t
$$

where $T$ is the period of induction, $d$ is the lamination thickness, $\sigma$ is the iron conductivity and $\rho$ is the iron density. To take into account the effects of rotational magnetic flux in the BDFM, the eddy current loss can be expressed as [19]:

$$
P_{e}=\frac{d^{2}}{12} \frac{1}{T} \int_{T}\left[\left(\frac{\partial B_{r}}{\partial t}\right)^{2}+\left(\frac{\partial B_{t}}{\partial t}\right)^{2}\right] d t
$$

TABLE II

Flux Density Along the MinOR AND MAJOR AXIS, AND THE ASPECT RATIO IN THE STATOR AND ROTOR IRON CIRCUITS

\begin{tabular}{lcccccc}
\hline Points & $B_{\text {minor }}(T)$ & $B_{\text {major }}(T)$ & $\lambda_{\mathrm{s}}$ & $B_{\text {minor }}(T)$ & $B_{\text {major }}(T)$ & $\lambda_{\mathrm{r}}$ \\
\hline \multicolumn{3}{c}{ Stator iron circuit } \\
\hline $\mathrm{P}_{1}$ & 0.56 & 1.82 & 0.31 & 0.37 & 1.60 & 0.23 \\
$\mathrm{P}_{2}$ & 0.50 & 1.83 & 0.27 & 0.32 & 1.48 & 0.23 \\
$\mathrm{P}_{3}$ & 0.41 & 1.87 & 0.22 & 0.19 & 1.31 & 0.15 \\
$\mathrm{P}_{4}$ & 0.14 & 1.63 & 0.09 & 0.06 & 1.41 & 0.04 \\
$\mathrm{P}_{5}$ & 0.11 & 1.51 & 0.07 & 0.04 & 1.53 & 0.03 \\
$\mathrm{P}_{6}$ & 0.88 & 1.29 & 0.68 & 0.18 & 1.62 & 0.11 \\
$\mathrm{P}_{7}$ & 0.66 & 1.25 & 0.53 & 0.18 & 1.25 & 0.14 \\
$\mathrm{P}_{8}$ & 0.34 & 1.46 & 0.23 & 0.10 & 0.98 & 0.10 \\
$\mathrm{P}_{9}$ & 0.09 & 1.46 & 0.06 & 0.05 & 0.69 & 0.07 \\
$\mathrm{P}_{10}$ & 0.10 & 1.44 & 0.07 & 0.07 & 0.91 & 0.08 \\
$\mathrm{P}_{11}$ & 0.31 & 1.46 & 0.21 & 0.06 & 1.03 & 0.06 \\
$\mathrm{P}_{12}$ & 0.45 & 1.49 & 0.30 & 0.22 & 1.07 & 0.21 \\
$\mathrm{P}_{13}$ & 0.06 & 1.49 & 0.04 & 0.04 & 0.91 & 0.04 \\
\hline
\end{tabular}

\section{Excess Losses}

Staumberger et. al. in [21] presented a new physical concept of Magnetic object. Under this concept, the magnetic domain wall movements dislocate other domain walls and they are all related in the same correlation region. Each correlation region corresponds a magnetic object. A magnetic field is originated by the currents created by the magnetic object movement. Therefore, an external field is needed to compensate this field, causing excess losses, which may exceed the eddy current loss predicted using the classical model of (4). The mean value of the excess loss is:

$$
P_{e x}=\frac{K_{e x}}{T_{T}}\left|\frac{d B}{d t}\right|^{1.5} d t
$$

$K_{e x}$ is the excess loss coefficient, which depends on the iron material characteristics. In the presence of rotational magnetic field in the iron circuit, the excess loss can be obtained from [18]:

$$
P_{e x}=\frac{K_{e x}}{T} \int_{T}\left[\left(\frac{d B_{r}}{d t}\right)^{2}+\left(\frac{d B_{t}}{d t}\right)^{2}\right]^{0.75} d t
$$

\section{Hysteresis Loss}

The hysteresis loss is the energy required to overcome the impedance of the domain walls motion, which occurs when a material is magnetised by defects in the magnetic material [22]. For the BDFM rotor iron circuit, where the main field components have the same frequency, the hysteresis loss is given by:

$$
P_{\text {hyst }}=f\left(P_{\text {hyst }}^{x}, P_{\text {hyst }}^{y}\right)
$$

where $P^{x}{ }_{h y s t}$ and $P^{y}{ }_{h y s}$ are the hysteresis losses computed for the spatially orthogonal components of the flux density, $x$ and $y$ in this case. This may be combined from different formulations to give the resulting hysteresis loss. Stumberger et. al. [21] showed that the formulations that have been used in the literature give core loss predictions that are not considerably different. Therefore, a simple summation is adopted. To take the effects of rotational rotor magnetic field into account, the hysteresis loss can be expressed as:

$$
P_{\text {hyst }}=P_{\text {hyst }}^{r}+P_{\text {hyst }}^{t}
$$

where $P^{r}{ }_{h y s t}$ and $P_{\text {hyst }}$ are given by

$$
\begin{gathered}
P_{\text {hyst }}^{r}=K_{\text {hyst }} f B_{p r} K\left(B_{r}(t)\right) \\
P_{\text {hyst }}^{t}=K_{\text {hyst }} f B_{p t} K\left(B_{t}(t)\right)
\end{gathered}
$$

$K_{\text {hyst }}$ and $\alpha$ are constants and determined by the core material characteristics. $\mathrm{K}(\mathrm{B}(\mathrm{t}))$ is an empirically determined minor loop correction factor to account for minor hysteresis loops that are caused by time harmonics in the flux densities and is given by [22]:

$$
K(B(t))=1+\frac{0.65}{B_{m}} \sum_{i} B_{i}
$$

where $\Delta B_{\mathrm{i}}$ is the difference between the local minimum and local maximum values of the flux density waveform.

The prediction of the stator hysteresis loss component requires a different approach because the stator flux density distribution in the BDFM is non-sinusoidal. It also has a DC offset at the natural speed. Hashemnia et. al. in [10] proposed a method to calculate the hysteresis loop area without the knowledge of the hysteresis loop shapes when the stator iron circuit is subjected to a non-sinusoidal magnetic flux density of the type in the BDFM. Accurate computation of the hysteresis loops requires that the hysteresis model be incorporated into the 
FE model when computing the magnetic field distribution [23]. Solving the resulting FE equations at each time-step will however involve hundreds of iterations, leading to excessive simulation time.

Belahcen et. al. [24] showed that the core loss can also be predicted accurately using $B$ and $H$ vectors that are computed using vector hysteresis model posteriori. It essentially means that $\mathrm{B}$, computed using non-linear single-valued B-H curve, is used as the input into a scalar hysteresis model in order to compute H. A scalar Preisach model is used to determine the static hysteresis magnetic field strength, $\mathrm{H}_{\text {hyst }}$, corresponding to a given magnetic flux density obtained from the FE simulation based on the Maxwell's equations. In the scalar Preisach hysteresis model, a ferromagnetic material is represented as a superposition of shifted rectangular elementary hysteresis operators with $h_{1}$ switching down and $h_{2}$ switching up fields. The magnetic flux density in this model is expressed as [25]:

$$
B(t)={ }_{T}\left(h_{1}, h_{2}\right)\left(h_{1}, h_{2}, H(t)\right) d h_{1} d h_{2}
$$

where $\left.\chi h_{1}, h_{2}, H(t)\right)$ represents the elementary operator and is equal to:

$$
\begin{aligned}
& \left(h_{1}, h_{2}, H\left(t_{k}\right)\right)= \\
& \begin{cases}1 & \text { if } H\left(t_{k}\right) \leq h_{1} \\
+1 & \text { if } H\left(t_{k}\right) \geq h_{2} \\
\left(h_{1}, h_{2}, H\left(t_{k 1}\right)\right) & \text { if } h_{1} \leq H\left(t_{k}\right) \leq h_{2}\end{cases}
\end{aligned}
$$

The $\mu\left(h_{1}, h_{2}\right)$ is the Preisach distribution function that can be considered as a weight for the elementary operator. Several expressions are given for the Preisach distribution in the literature, one is proposed by [26] as:

$$
\left(h_{1}, h_{2}\right)=\left(h_{1}\right)\left(h_{2}\right)
$$

where $\varphi$ is a one-dimensional function. For a ferromagnetic iron material used in electrical machines' lamination, $\varphi$ can be represented by:

$$
(x)=\frac{a e^{x}}{\left(1+b e^{x}\right)^{2}}
$$

where $a$ and $b$ are dependent on the material characteristics and are obtained from the lamination B-H curves. It was shown in [26] that the gradient of flux density over magnetic field strength can be expressed as:

$$
\frac{d B}{d H}=2 \quad(H){ }_{H}^{H} \quad\left(h_{1}\right) d h_{1}
$$

By numerical integration of (17), the hysteresis field strength $H_{\text {hyst }}$ for a given flux density value can be obtained. Finally, the hysteresis loss component is obtained by numerical computation of the following equation [25]:

$$
P_{\text {hyst }}=\frac{1}{T} \quad H \cdot \frac{B}{t} \cdot d t
$$

The proposed iron loss computation procedure is summarised in Fig. 5.

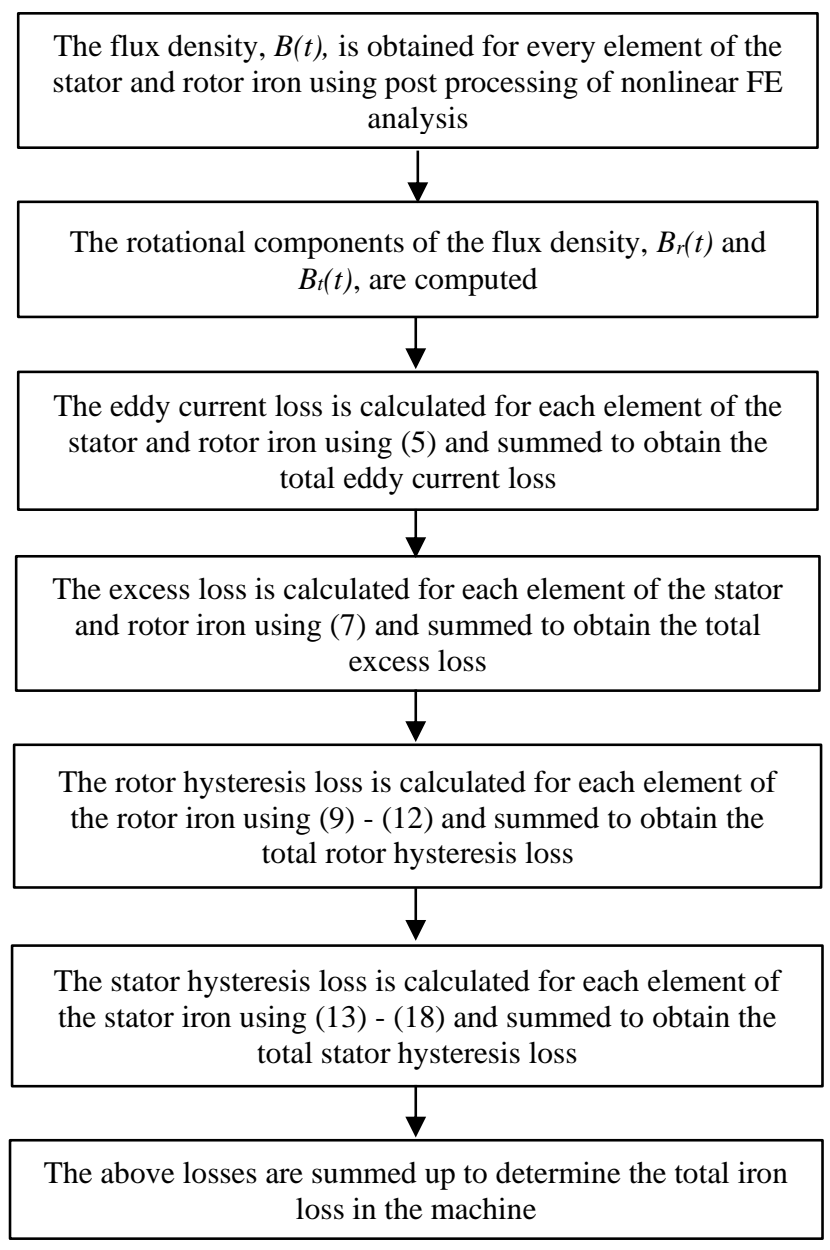

Fig. 5: Proposed iron loss calculation procedure (i.e. Model 3).

\section{CAlCUlation OF BDFM IRON Loss CoEFFICIENTS}

The conventional three-term iron loss model of (2) uses material-dependent coefficients for the iron loss terms. However, the use of constant coefficients may not be practical in some operating conditions, especially when a non-sinusoidal magnetic field is present [27]. Chen et. al. proposed a model with constant coefficients for the eddy-current and excess losses and variable coefficients for the hysteresis loss [28]. In [27] a mathematical procedure was proposed to determine the iron loss coefficients which are varied with frequency and flux density. The method was shown to give good estimation of iron losses in the laminations when compared to experiments.

The specific core loss data for the BDFM lamination (type M530-65A as given in Table I) have been obtained from Epstein frame loss measurements, where the sample under test is subjected to sinusoidal excitation on the primary winding, while the open-circuit voltage on the secondary is measured [29]. The measured specific core losses for a frequency range of $10-50 \mathrm{~Hz}$ and flux densities from 0.5 to $2 \mathrm{~T}$ are shown in Fig. 6 . It is then possible to obtain the variable loss coefficients by fitting loss data as described below.

Under a sinusoidal alternating excitation, the specific core losses $\mathrm{w}_{\mathrm{Fe}}$ in watts per kilogram can be expressed as:

$$
w_{F e}=K_{e} f^{2} B^{2}+K_{e x} f^{1.5} B^{1.5}+K_{h y s t} f B
$$


In the first step of identifying the coefficients, (19) is divided by frequency resulting in:

$$
\frac{w_{F e}}{f}=a+b \sqrt{f}+c(\sqrt{f})^{2}
$$

where

$$
a=K_{\text {hyst }} B, \quad b=K_{e x} B^{1.5}, \quad c=K_{e} B^{2}
$$

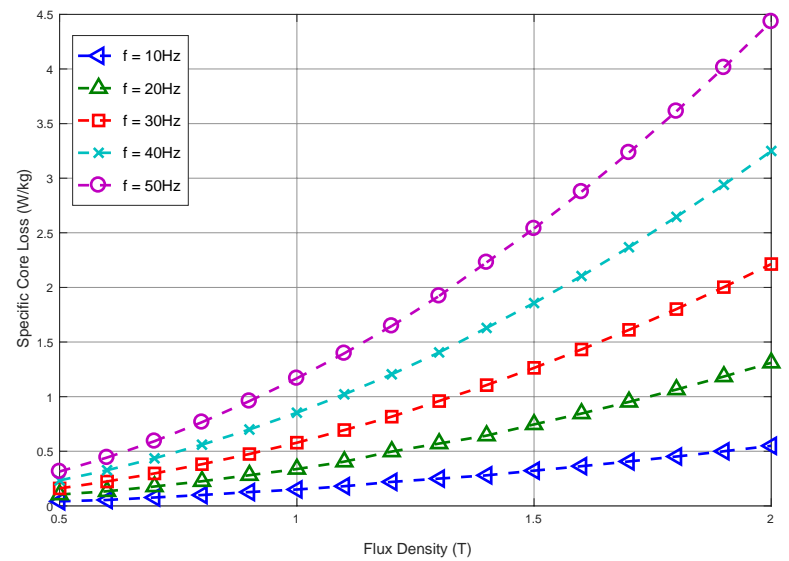

Fig. 6. Specific core loss for ranges of frequency and flux density in the lamination sheet obtained from experiments.

The coefficients $a, b$, and $c$ are determined by quadratic fitting based on a minimum of three points. Fig. 7 shows ratio of core loss to frequency $\frac{w_{F e}}{f}$ as a function of $\sqrt{f}$ according to (20) for different flux densities. Each curve is obtained from five measurements carried out at the same flux density but different frequencies to improve the accuracy of the numerical procedure.

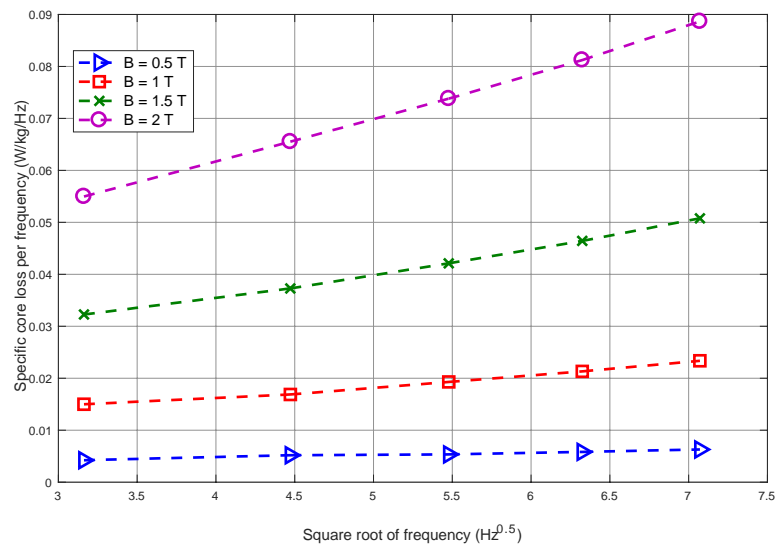

Fig. 7. Specific core loss per frequency versus square root of frequency.

The eddy current coefficient $K_{e}$ and the excess loss coefficient $K_{e x}$ are derived from specific core loss measurements for a single lamination using (20) at different values of flux density. These coefficients are independent of frequency, but unlike those for conventional models, they show a significant variation with flux density as illustrated in Figs. 8 and 9. Hence, the following third-order polynomials were employed for curve fitting to obtain $K_{e}$ and $K_{e x}$ :

$$
\begin{gathered}
K_{e}=K_{e 0}+K_{e 1} B+K_{e 2} B^{2}+K_{e 3} B^{3} \\
K_{e x}=K_{e x 0}+K_{e x 1} B+K_{e x 2} B^{2}+K_{e x 3} B^{3}
\end{gathered}
$$

In order to identify the power $\alpha$ for the hysteresis loss, a third-order polynomial is used:

$$
\alpha=\alpha_{0}+\alpha_{1} B+\alpha_{2} B^{2}+\alpha_{3} B^{3}
$$

Substituting (24) in (21) and applying a logarithmic operator, it can be shown that:

$$
\log a=\log K_{\text {hyst }}+\left({ }_{0}+{ }_{1} B+{ }_{2} B^{2}+{ }_{3} B^{3}\right) \log B
$$

Coefficient $a$ represents the ratio of hysteresis loss to frequency and is extracted from (20) after substituting $b, c, K_{e}$ and $K_{e x}$ with (21) - (23). The logarithm of $a$ versus flux density is shown in Fig. 10. As can be seen, there are two regions with distinct variation patterns and therefore two flux density regions may be defined which approximately include the ranges $0.5-1.2$ $\mathrm{T}$ and $1.2-2 \mathrm{~T}$. It is worth noting that in [30] and [27], a tworegion and a three-region approximation of $K_{\text {hyst }}$ and $\alpha$ was used, respectively. For a given frequency and flux density range, (25) is solved by linear regression using at least five values for $\log B$. The hysteresis loss parameters for different frequencies and flux density ranges are obtained as shown in Table III.

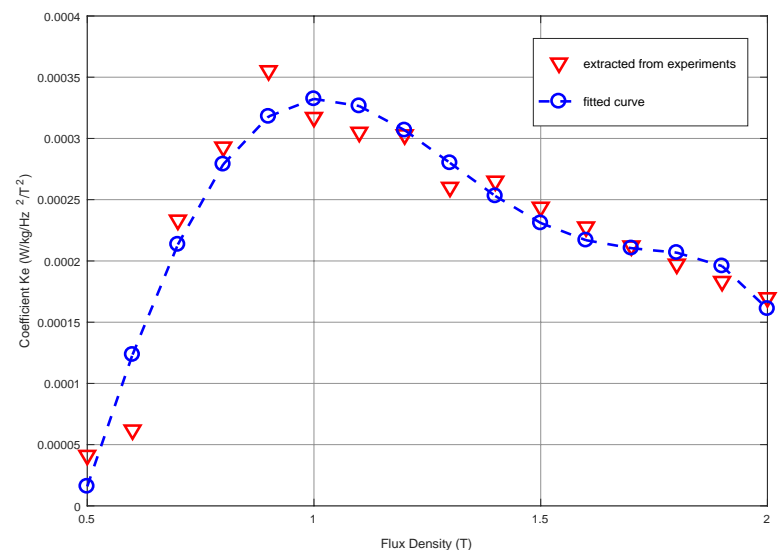

Fig. 8. Variation of the eddy current coefficient with flux density. $K_{e}$ is independent of frequency.

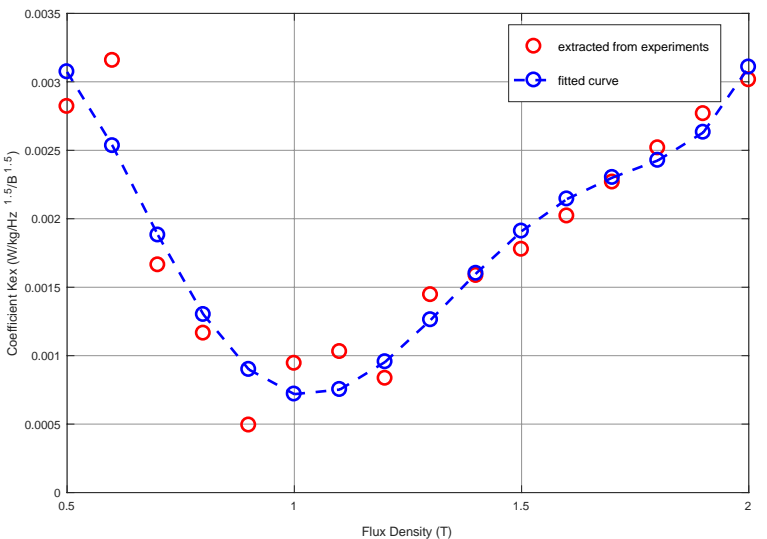

Fig. 9. Variation of the excess loss coefficient with flux density. $K_{e x}$ is independent of frequency.

The specific core loss at different flux density and frequency is calculated from (19) using the parameters extracted from experimental test, and results are compared in Fig. 11 with measured losses. The relative error between the estimated and measured specific core losses is less than 9\% across all measurements. 


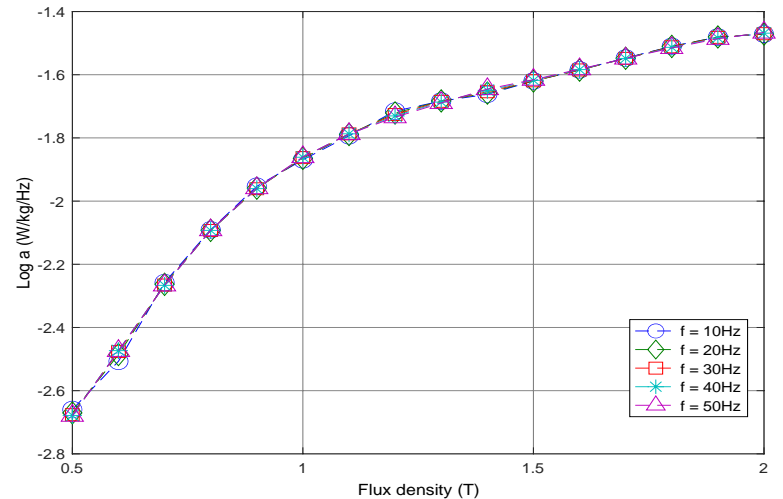

Fig. 10. Logarithm of the ratio of hysteresis loss to frequency. Curves for different frequencies are overlapping.

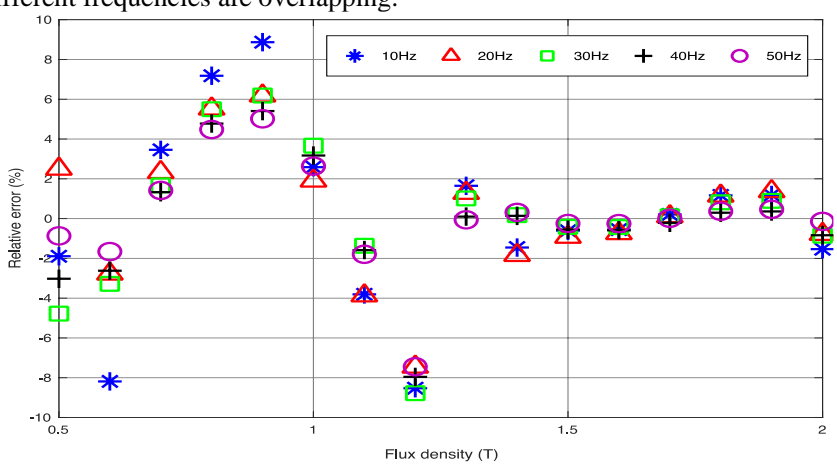

Fig. 11. Relative error between calculated and measured specific core losses at various flux and frequency conditions.

\section{BDFM IRON LOSS COMPUTATION}

The specifications of the prototype BDFM considered in this study are given in Table I. The FE analysis of the machine is performed using a commercial software application EFFE [14]. A voltage-fed time-stepping analysis is used to compute the flux density in the stator and rotor iron circuits when the BDFM is operating in the synchronous mode. A 2-D FE model is developed to reduce the computational time by assuming that the effects of axial flux are negligible. The end region leakage effects are incorporated into the analysis using lumped parameters [3]. The modelling is performed using the timestepping method for accurate analysis and took into account the nonlinear properties of the iron.

In order to validate the proposed iron loss computation method, an open-circuited rotor shown in Fig. 12 is used. Thus, the total iron losses can be obtained from no-load locked-rotor tests using stator winding measurements since both mechanical and rotor copper losses are eliminated.

$$
P_{\text {iron }}=P_{\text {in }} P_{c u \text { PW }} P_{c u C W}
$$

$P_{\text {in }}$ is the total input power to stator $\mathrm{PW}$ and $\mathrm{CW}$ and the $P_{c u-}$ ${ }_{P W}$ and $P_{C u-C W}$ are the copper losses dissipated in the stator PW and $\mathrm{CW}$, respectively.

Once the FE model is solved, the local flux density waveforms for both the stator and rotor regions are extracted from the FE solution. The flux density data for every element in the mesh at each time-step is logged in a file for further analysis. The process is incremented to the next time-step and repeated until the required data for a complete period of the flux density is obtained. Each data set includes the element number, the $\mathrm{x}$ and $\mathrm{y}$ components of the flux density, are the coordinates of the centroid of the elements. Initially, the data is processed to decompose the flux density into radial and tangential components, enabling the losses resulting from rotational flux patterns in the stator and rotor laminations to be calculated.

TABLE III

HYSTERESIS LOSS PARAMETERS FOR THE LAMINATION STEEL

\begin{tabular}{cccc}
\hline Flux Density $(T)$ & $\begin{array}{c}\text { Frequency } \\
(\mathrm{Hz})\end{array}$ & $K_{\text {hyst }}\left(\mathrm{W} / \mathrm{Kg} / \mathrm{Hz} / \mathrm{T}^{\alpha}\right)$ & $\alpha$ \\
\hline \multirow{3}{*}{$0.5<\mathrm{B}<1.2$} & 10 & 0.0132 & 2.5787 \\
& 20 & 0.0132 & 2.5748 \\
& 30 & 0.0132 & 2.5716 \\
& 40 & 0.0131 & 2.5685 \\
& 50 & 0.0131 & 2.5651 \\
\hline \multirow{3}{*}{$1.2<\mathrm{B}<2$} & 10 & 0.0147 & 1.2311 \\
& 20 & 0.0148 & 1.2219 \\
& 30 & 0.0149 & 1.2150 \\
& 40 & 0.0149 & 1.2092 \\
& 50 & 0.0150 & 1.2042 \\
\hline
\end{tabular}

Next, the local loss densities are calculated for the radial and tangential components of the flux density, then summed to give the elemental iron loss density. The local eddy current and excess loss densities for every element are computed using (5) and (7), respectively. The local hysteresis loss density for the rotor elements are computed using (9) - (12). For the stator iron circuit, however, the scalar Preisach model presented in Section III-D is employed to compute the hysteresis loss for each element using (13) - (18). These iron loss densities are multiplied by the mass of the iron calculated using the element areas and length of the iron core. Finally, these localised iron losses are summed to give the total iron loss dissipated in the machine.

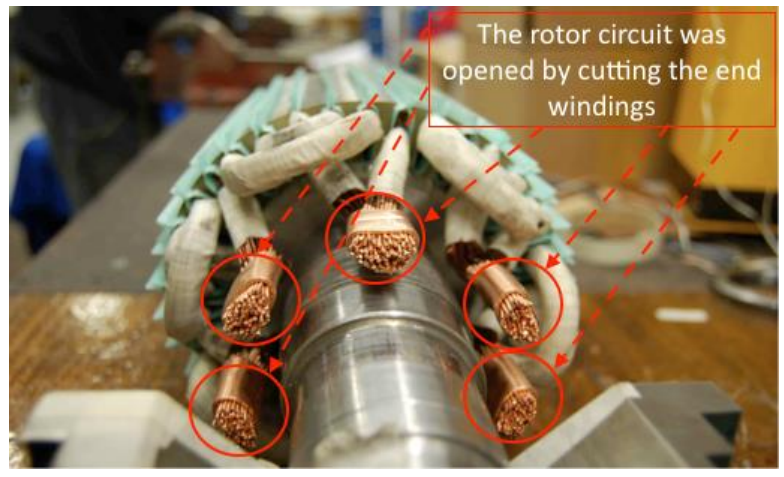

Fig. 12. The BDFM rotor used in this study with open-circuited winding.

\section{EXPERIMENTAL VALIDATION OF THE BDFM IRON LOSS MODEL}

The test bench for the BDFM is shown in Fig. 13. The machine is operated at the no-load locked-rotor condition with an open-circuited rotor winding. The delta-connected PW is connected to the grid through a variac and is supplied at 230 Vrms, $50 \mathrm{~Hz}$. The CW is also connected in delta and supplied by a unidirectional converter at a constant $V / f$ ratio. A sinusoidal filter is connected between the converter output and the $\mathrm{CW}$ to 
filter out the harmonics produced by the converter's switching frequency. At each $\mathrm{CW}$ voltage level, the iron loss is measured using (26) by subtracting the PW and CW copper losses from the input power. The per-phase resistance values of PW and CW were obtained by DC measurements and are $6.3 \Omega$ and 3.9 $\Omega$, respectively. The voltages and currents of each stator phase are measured by LEM LV 25-p and LEM LTA 100-p transducers, respectively. A V/f control algorithm is implemented in MATLAB, which generates PWM signals for the converter.

Three different modelling approaches are used to compute the BDFM iron losses as described below. A summary of the iron loss models is also shown in Table IV.

- Model 1 uses iron loss equations of (4), (6) and (8) for computing eddy current, excess and hysteresis losses, respectively. It ignores the presence of rotational fields in the BDFM.

- Model 2 takes into account the rotational characteristics of the magnetic field by using (5) and (7) for computing eddy current and excess losses, respectively, and (9) - (12) for computing hysteresis losses in the stator and rotor iron.

- Model 3, proposed in this paper, uses the same method as Model 2 to calculate eddy current, excess and rotor hysteresis losses. However, it employs (13) - (18) for the calculation of stator hysteresis loss.

Fig. 14 compares the iron losses computed from the above three models with experimental results at different $\mathrm{CW}$ voltages. Close agreement can be seen between the computational results from Model 3 and experimental measurements which validates the practicality of the proposed iron loss modelling approach for the BDFM. The rise in the iron losses as the $\mathrm{CW}$ voltage is increased is due to the increase in the CW supply frequency set by the v/f controller.

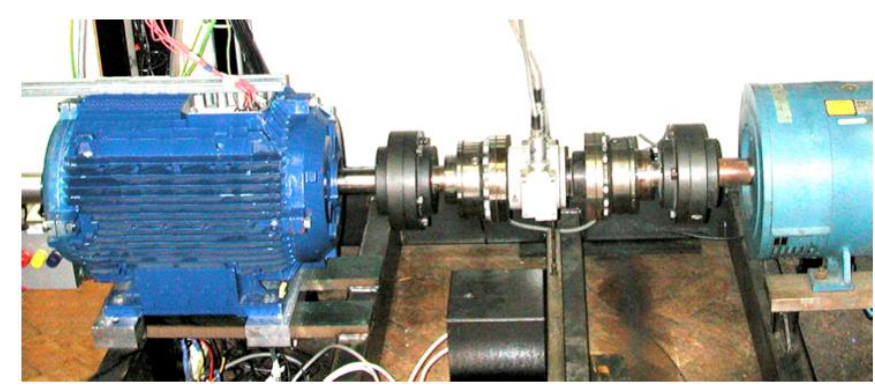

Fig. 13. Prototype D160 BDFM on the test rig.

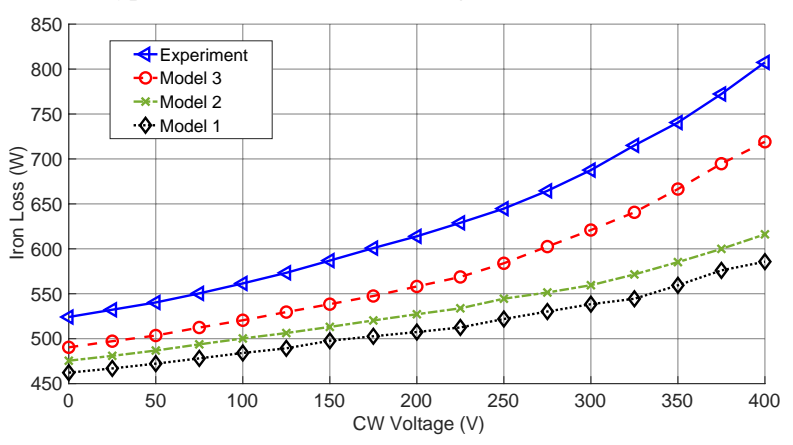

Fig. 14. Iron loss values at different $\mathrm{CW}$ voltages, obtained from experiments and iron loss models. $\mathrm{V}_{\mathrm{pw}}=230 \mathrm{~V}$ and $\mathrm{f}_{\mathrm{pw}}=50 \mathrm{~Hz}$.
TABLE IV

THE EQUATIONS USED IN CONSIDERED IRON LOSS MODELS. MODELS 1 AND 2 ARE CONVENTIONAL IRON LOSS MODELS AND MODEL 3 IS THE ONE PROPOSED IN THIS PAPER.

\begin{tabular}{ccccc}
\hline & $\begin{array}{c}\text { Eddy } \\
\text { current loss }\end{array}$ & $\begin{array}{c}\text { Excess } \\
\text { loss }\end{array}$ & $\begin{array}{c}\text { Rotor hysteresis } \\
\text { loss }\end{array}$ & $\begin{array}{c}\text { Stator } \\
\text { hysteresis loss }\end{array}$ \\
\hline Model 1 & $(4)$ & $(6)$ & $(8)$ & $(8)$ \\
\hline Model 2 & $(5)$ & $(7)$ & $(9)-(12)$ & $(9)-(12)$ \\
\hline Model 3 & $(5)$ & $(7)$ & $(9)-(12)$ & $(13)-(18)$ \\
\hline
\end{tabular}

Fig. 15 shows the relative error between the iron losses measured by experiment and computed by the models. The highest error is attributed to Model 1, as expected. The error associated to Model 2 is noticeably lower than Model 1, which shows that the rotational characteristics of the magnetic field have important effects on the machine iron losses. The least error, by far, is due to Model 3. Larger error is generally seen as the $\mathrm{CW}$ voltage is increased, which is mainly because of excessive saturation of the iron circuit, especially in the stator teeth where the highest levels of flux density exist, leading to additional losses that are not modelled by the analytical methods.

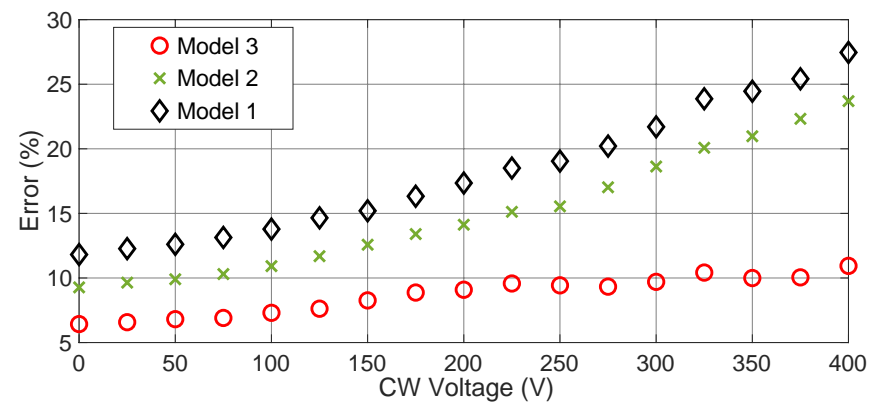

Fig. 15. Relative error between the measured and modelled iron losses.

Fig. 16 shows the breakdown of the iron loss components computed using Models 1, 2 and 3. As it is evident from Figs. $16 \mathrm{a}$ and 16b, the loss curves follow a similar rising trend, however, accounting for the rotational characteristics of the magnetic fields in Models 2 and 3 has led the eddy current, excess and rotor hysteresis losses to be notably larger throughout the $\mathrm{CW}$ voltage range compared to when those effects are ignored in Model 1.

The most noticeable difference can be observed in the stator hysteresis loss computed by Model 3 compared to Models 1 and 2. The difference becomes significant above the CW voltage of $200 \mathrm{~V}$ where the hysteresis loss increases sharply in Model 3, while only a slight increase can be observed in Model 1 and 2. This explains the significant difference between the predictions of Models 2 and 3 in Fig. 14 above the CW voltage of 200. Thus, the proposed stator hysteresis model given by (13) - (18) has enabled the iron loss predictions by Model 3 to closely trace the experimental results, maintaining the error within an acceptable range of 6 to $11 \%$.

Consequently, it can be concluded that the conventional method used in Model 1 for iron loss calculation, which was originally developed for electrical machines with single frequency and alternating magnetic fields is not suitable to the BDFM with a complex magnetic field pattern resulted from the presence of two magnetic fields with different frequencies and pole numbers. In addition, while incorporating the rotational 
magnetic field effects into the conventional model i.e. Model 2 has improved the accuracy of iron loss prediction, there is still significant disagreement between the predicted and measured iron loss values.

The proposed iron loss model in this study i.e. Model 3, has led to significant improvement in the accuracy of iron loss prediction in the BDFM. This is mainly because, in comparison with Model 2, the scalar Preisach model has been utilised for the calculation of stator hysteresis loss which is known to give more accurate estimate when nonlinear and non-stationary magnetic fields are present, as in the BDFM.

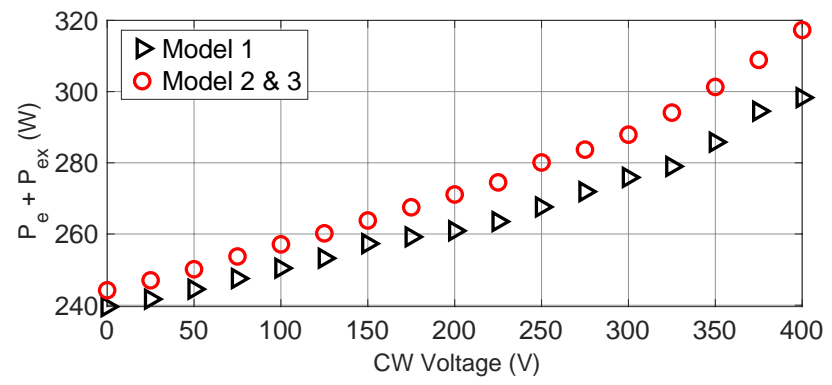

(a)

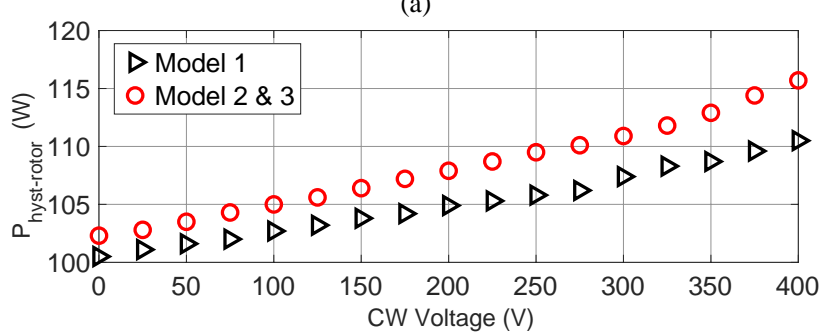

(b)

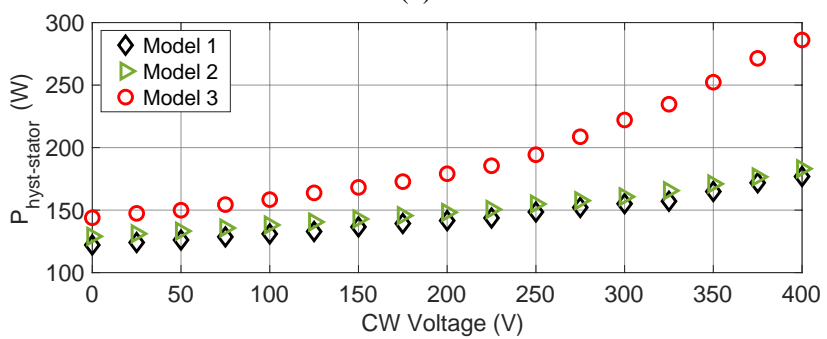

(c)

Fig. 16. Iron loss components computed by Models 1 to 3; (a) sum of eddy current and excess losses, (b) rotor hysteresis loss, (c) stator hysteresis loss.

\section{CONCLUSIONS}

In this paper, a new approach for modelling the iron losses in the BDFM has been proposed. The iron loss calculation is particularly challenging for the BDFM since two magnetic fields with different frequencies and pole numbers are present in the iron circuit. This causes a nonlinear magnetic field to be induced in the BDFM stator iron with a DC offset and hence the conventional hysteresis models may not be suitable for computing the stator hysteresis losses. A new method based on the scalar Preisach model has been developed to estimate the hysteresis loss in the stator. It essentially uses the flux density computed from the FE model that incorporates a nonlinear single-valued B-H curve to compute $\mathrm{H}$ by utilising the scalar hysteresis model. Then the computed $\mathrm{B}$ and $\mathrm{H}$ values are used to calculate the stator hysteresis losses. The effects of rotational magnetic field have also been considered in the iron loss model.
The main limitation of the proposed method is that iron losses are calculated offline from post-processing of FE results, which compromises the accuracy of iron loss calculations. Nevertheless, experimental tests, conducted on a laboratory BDFM, has validated the proposed model, with predictions being $<11 \%$ lower than measurements.

It is worth noting that although the proposed iron loss model is developed and verified on a $10 \mathrm{~kW}$ laboratory BDFM, the loss calculation procedure can be generalised and applied to larger machines and with different designs and configurations. Future work may include more accurate measurement of iron losses using calorimetric measurements and the thermal modelling of the machine for further optimisation of the thermal design. In addition, by utilising a wireless rotor current measurement technique, as shown in [31], iron losses may be measured at more practical operating conditions, especially when the machine is loaded.

\section{REFERENCES}

[1] A. R. W. Broadway and L. Burbridge, "Self-cascaded machine: A lowspeed motor or high frequency brushless alternator," IEE Proceedings of Institution of Electrical Engineers, Vol. 117, no. 7, pages 1277-1290, 1970.

[2] S. Müller, M. Deicke, and R. M. deDoncker. "Doubly fed induction generator systems for wind turbines," IEEE Industry Applications Magazine, pp. 26-33, May/June 2002.

[3] S. Abdi, E. Abdi, A. Oraee, R. McMahon, "Equivalent circuit parameters for large brushless doubly fed machines", IEEE Transactions on Energy Conversion, Vol. 29, No. 3, Sep 2014.

[4] A. Oraee, R. McMahon, E. Abdi, S. Abdi, S. Ademi, "Influence of Polepair Combinations on the Characteristics of the Brushless Doubly Fed Induction Generator", IEEE Transactions on Energy Conversion, Vol. 35, pp. 1151-1159, September 2020.

[5] S. Abdi, D. LIano, E. Abdi, P. Malliband, R. McMahon, "Experimental analysis of noise and vibration for large brushless doubly fed machines", IET The Journal of Engineering, Vol. 2017, pp. 724-728, 2017.

[6] F. Shibata and K. Taka. "Speed control for brushless cascade induction motors in control range of slips $\mathrm{s} 1>1$ and s $2>1$," IEEE Transactions on Energy Conversion, Vol. EC2. pp. 246-253, June 1987.

[7] M. Ahmadian, B. Jandaghi, H. Oraee, "Hysteresis loss in brushless doubly fed induction machines", The International Conference on Renewable Energies and Power Quality, pp. 975-980, May 2011.

[8] A. Ferreira, S. Williamson, "Time-stepping finite-element analysis of brushless doubly fed machine taking iron loss and saturation into account", IEEE Transactions on Industry Applications, Vol 35, No. 3, pp. 583-588, May 1999.

[9] F. Zhang, S. Yu, Y. Wang, S. Jin, M. Jovanovic, "Design and Performance Comparisons of Brushless Doubly-Fed Generators with Different Rotor Structures", IEEE Transactions on Industrial Electronics, Vol. 66, pp. 631-640, January 2019.

[10] M. Hashemnia, F. Tahami, E. Oyarbide, "Investigation of core loss effect on steady-state characteristics of inverter fed brushless doubly fed machines", IEEE Transactions on Energy Conversion, Vol. 29, No. 1, pp. 57-64, March 2014.

[11] S. Yu, Y. Zhang, C. Chen, F. Zhang, H. Nian, "Loss estimation of brushless doubly fed generator with hybrid rotor considering multiple influence factors", IEEE Access, Vol. 8, 2020.

[12] I. Scian, D. G. Dorrell1, and P. J. Holik, "Assessment of Losses in a Brushless Doubly-Fed Reluctance Machine," IEEE Transactions on Magnetics, Vol. 42, no. 10, October 2006.

[13] D. G. Dorrell1, A. M. Knight, and R. E. Betz, "Issues with the Design of Brushless Doubly-Fed Reluctance Machines: Unbalanced Magnetic Pull, Skew and Iron Losses," Electric Machines \& Drives Conference (IEMDC), 2011 IEEE International, 15-18 May 2011.

[14] S. Abdi Jalebi, E. Abdi, R. McMahon, "Numerical Analysis of Stator Magnetic Wedge Effects on Equivalent Circuit Parameters of Brushless Doubly Fed Machines," International Conference on Electrical Machines (ICEM), pp. 879-884. October 2018. 
[15] A. Oraee, E. Abdi, S. Abdi, R. McMahon, "Effect of rotor winding structure on the BDFM equivalent circuit parameters", IEEE Transactions on Energy Conversion, Vol. 30, No. 4, Dec 2015.

[16] S. Williamson, A. C. Ferreira, and A. K. Wallace. "Generalized theory of the brushless doubly-fed machine part 1: Analysis," IEE Proceedings Electrical Power Applications, pp. 111-122, 1997.

[17] L. Ma, M. Sanada, S. Morimoto, and Y. Takeda. "Prediction of iron loss in rotating machines with rotational loss included," IEEE Transactions on Magnetics, Vol. 39, No. 4, July 2003.

[18] C. A. Hernandez-Aramburo, T. C. Green, and A. C. Smith, "Estimating rotational iron losses in an induction machine," IEEE Transactions on Magnetics, Vol. 39, no. 6, Nov. 2003.

[19] C. A. Hernandez-Aramburo, T. C. Green, and A. C. Smith, “Assessment of power losses of an inverter-driven induction machine with its experimental validation," IEEE Transaction on Industry Applications., Vol. 39, pp. 994-1004, July-Aug. 2003.

[20] T. Kochmann, "Relationship between rotational and alternating losses in electrical steel sheets," Journal of Magnetism and Magnetic Materials. Vol. 160, pp. 145-146, July 1996.

[21] B. Stumberger, V. Gorican, G. Stumberger, A. Hamler, M. Trlep, and M. Jesenik. "Accuracy of iron loss calculation in electrical machines by using different iron loss models". Journal of Magnetism and Magnetic Materials, pages 269-271, 2003.

[22] J.D. Lavers, P.P. Biringer, and H. Hollitscher. "A simple method of estimating the minor loop hysteresis loss in thin laminations". IEEE Transactions on Magnetics, Vol. 14, 386-388, 1978.

[23] M.E. Mathekga, R.A. McMahon, and A.M. Knight. "Application of the fixed point method for solution in time-stepping finite element analysis using the inverse vector jiles-atherton model". IEEE Transactions on Magnetics, Vol. 47, pp. 3048-3051, October 2011.

[24] A. Belahcen, E. Dlala, K. Fonteyn, M. Belkasim, "A posteriori iron loss computation with a vector hysteresis model", The International Journal for Computing and Mathematics in Electrical and Electronic Engineering, Vol. 29, No. 6, 2010.

[25] Julius Saitz, "Magnetic Field Analysis of Electric Machines Taking Ferromagnetic Hysteresis into Account”, PhD thesis, Helsinki University of Technology, 2001.

[26] Z. Szabo, I. Tugyi, G. Kadar, J. Fuzi, "Identification procedures for scalar Preisach model", Elsevier Physica B: Condensed Matter, Vol. 343, pp. 143-147, 2004.

[27] D. Ionel, M. Popescu, S. J. Dellinger, T. J. E. Miller, R. J. Heideman, and M. I. McGilp, "On the variation with flux and frequency of the core loss coefficients in electrical machines," IEEE Transactions on Industry Applications, Vol. 42, no. 3, May 2006.

[28] Y. Chen and P. Pillay, "An improved formula for lamination core loss calculations in machines operating with high frequency and high flux density excitation," in Proc. IEEE 37th IAS Annu. Meeting, Pittsburgh, PA, Oct. 2002, pp. 759-766.

[29] J, Geisinger, A. Knight "Investigation of iron losses in mixed frequency flux density waveforms", IEEE Transactions on Magnetics, Vol. 50, No. 11, November 2014.

[30] H. Domeki, Y. Ishihara, C. Kaido, Y. Kawase, S. Kitamura, T. Shimomura, N. Takahashi, T. Yamada, and K. Yamazaki, "Investigation of benchmark model for estimating iron loss in rotating machine," IEEE Transactions on Magnetics., Vol. 40, no. 2, pp. 794-797, Mar. 2004.

[31] D. LIano, S. Abdi, M. Tatlow, E. Abdi, R. McMahon, "Energy harvesting and wireless data transmission system for rotor instrumentation in electrical machines", IET Power Electronics, Vol 10, pp. 1259-1267, 2017.

\section{REFERENCES}

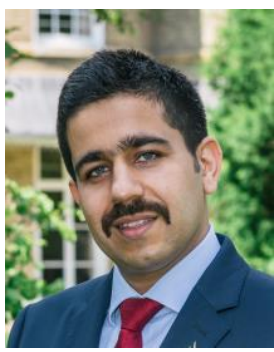

Salman Abdi received the B.Sc. degree from Ferdowsi University, Mashhad, Iran, in 2009, and the M.Sc. degree from the Sharif University of Technology, Tehran, Iran, in 2011, both in electrical engineering. He then completed the Ph.D. degree in electrical machines design and optimisation from Cambridge University, Cambridge, U.K, in 2015. $\mathrm{He}$ is currently an Assistant Professor in Electrical Engineering at the University of East Anglia (UEA), Norwich, UK. His main research interests include electrical machines and drives for renewable power generation and automotive applications.

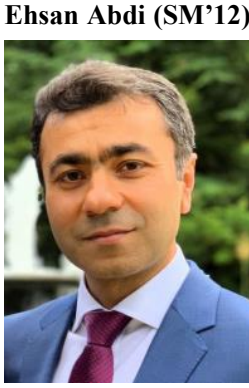

the B.Sc. degree from the Sharif University of Technology, Tehran, Iran, in 2002, and the M.Phil. and $\mathrm{Ph} . \mathrm{D}$. degrees, from Cambridge University, Cambridge, U.K., in 2003 and 2006, respectively, all in electrical engineering. $\mathrm{He}$ is currently the Managing Director of Wind Technologies Ltd., Cambridge, where he has been involved with commercial exploitation of the brushless doubly fed induction generator technology for wind power applications. He became a Senior Member of the IEEE in 2012. His main research interests include electrical machines and drives, renewable power generation, and electrical measurements and

instrumentation

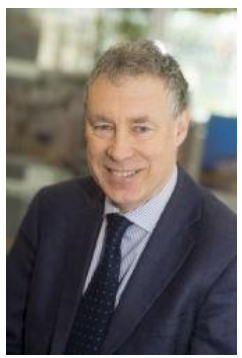

Richard McMahon received the B.A. degree in electrical sciences and the Ph.D. degree from the University of Cambridge, Cambridge, U.K., in 1976 and 1980, respectively. Following post-doctoral work on semiconductor device processing, he became a University Lecturer in electrical engineering with the Engineering Department, University of Cambridge, in 1989, where he was a Senior Lecturer in 2000. In 2016 he joined the Warwick Manufacturing Group (WMG), University of Warwick, Coventry, U.K., as a Professor of power electronics. His current research includes electrification of transport. electrical machines, power electronics and the 